\title{
Photocatalytic membrane modules for drinking water purification in domestic and community appliances ${ }^{\dagger}$
}

\author{
Ignazio Renato Bellobono, ${ }^{1, \neq}$ Franca Morazzoni, ${ }^{2}$ and Paola Maria Tozzi ${ }^{3}$ \\ ${ }^{1}$ Environmental Research Centre, University of Milan; via C. Golgi, 19; I-20133 Milan, Italy \\ ${ }^{2}$ Department of Materials Science, University of Milano Bicocca; I-20126, Milan, Italy \\ ${ }^{3}$ R\&D Group, B.I.T. srl; I-20121 Milan, Italy
}

\begin{abstract}
In the present paper, the performance of a pilot plant for domestic use was investigated, able to operate continuously, and in which tap water was fed (inorganic carbon IC: $81.6 \pm 0.5 \mathrm{ppm}$; total organic carbon TOC content: $1.52 \pm 0.02 \mathrm{ppm}$ ). This plant produced $130 \mathrm{~L} / \mathrm{d}$ of purified water. The tap water was first subjected to a prefiltration by a membrane microfiltration unit, followed by filtration through a membrane immobilising activated carbon, then through a reverse osmosis membrane, at a transmembrane pressure of 4 bar, and finally through a photocatalytic membrane unit, constituted by a metallic membrane, onto which the semiconductor and its photopromoters were present as a 3-4 $\mu \mathrm{m}$ thick surface layer, directly produced on the nanotechnologically treated surface of this membrane, irradiated at a power of $9.6 \mathrm{~W}$ in the range of optical absorption by semiconductor. Efficiency of these operations was compared by carrying out parallel experiments, using two other commercial plants (I and II), in which the photocatalytic treatment was not provided for. All the three plants were able to soften the tap water down to 6-8 ppm IC, but, as regards TOC, (I) yielded a purified water still containing $1.12 \pm 0.05 \mathrm{ppm}$ of organic carbon, and (II) $0.908 \pm 0.009 \mathrm{ppm}$, while the TOC content of water purified in the pilot plant of present work was lowered down to $0.06 \pm 0.02 \mathrm{ppm}$. In order to compare further efficiency of these plants, a simulated feed solution was treated, containing $3.05 \mathrm{ppm}$ of humic acids, or $2.16 \mathrm{ppm}$ of atrazine, or $4.23 \mathrm{ppm}$ of symazine. Reverse osmosis, which was present in all the three kind of plants examined, even if coupled with active carbon adsorption, was not able to remove entirely contamination due to organic micropollutants. This goal, on the contrary, was successfully achieved by the plant fitted with the photocatalytic membrane unit, particularly by considering that this plant showed substantially the same abatement efficiencies of plants (I) and (II), if the photocatalytic unit was switched off.
\end{abstract}

\section{INTRODUCTION}

The contamination of natural and drinking waters supplies and of the aquifers in general by insecticides, pesticides, and chemicals is the object of serious alarm, particularly in Countries with intensive agricultural and industrial activities. Conventional water treatments, such as coagulation, precipitative softening, filtration and chlorination, and even the more sophisticated membrane processes, such as nanofiltration and reverse osmosis, are ineffective for reducing concentration of many hazardous or toxic pollutants, especially if they are present in microquantities. Moreover, chlorination itself or ozonation are notoriously a source of pollutant production, as a result of reaction between naturally occurring humic substances and these disinfecting chemicals. For this reason, wholly alternative and innovating techniques, based on the use of semiconductor particulate systems to carry out the total oxidation of organic water contaminants, principally in the presence of titanium dioxide, are seeing a remarkable growth. However, only supporting or immobilisation of the photocatalytic system may represent the winning way towards a technological, economic,

\footnotetext{
${ }^{\dagger}$ Part 75 of the series "Photosynthetic Membranes"
}

‡E-mail: ignazio.bellobono@unimi.it; crai@unimi.it and consequently industrial solution by these advanced oxidation processes, as it has been shown, since the beginning of the past three quinquennia [1]. Immobilisation technologies, which have been studied in the present series of papers, are based on the production of photocatalytic membranes by which it is possible to incorporate promoting photocatalysts or photosensitizers together with the semiconductor, and exploiting at the same time all known advantages of membrane processes (modularity, optimal photoreactor modeling, continuous processing, potential separations, and so on).

In the present paper, a pilot plant for domestic use was investigated, operating continuously, and in which the tap water was fed (inorganic carbon IC: $81.6 \pm 0.5 \mathrm{ppm}$; total organic carbon TOC content: $1.52 \pm$ $0.06 \mathrm{ppm}$ ). This plant was able to produce $130 \mathrm{~L} / \mathrm{d}$ of purified water. The tap water was first subjected to a prefiltration by a membrane microfiltration unit, followed by filtration through a membrane immobilising activated carbon [2], then through a reverse osmosis membrane, at a transmembrane pressure of $4 \mathrm{bar}$, and finally through a photocatalytic membrane unit, constituted by a metallic membrane, onto which the semiconductor and its photopromoters were present as a 3-4 $\mu \mathrm{m}$ thick surface layer, directly produced on the 
nanotechnologically treated surface of this membrane. The photocatalytic membrane absorbed a radiating power of $9.6 \pm 0.4 \mathrm{~W}$ in the range of optical absorption spectrum of semiconductor (from $395 \mathrm{~nm}$ downwards).

Efficiency of these operations was compared by carrying out parallel experiments, using two other commercial plants (I and II), in which the photocatalytic treatment was not provided for.

In order to compare further efficiency of these plants, as regards integral photomineralisation of organic micropollutants present in groundwaters, simulated feed solutions were treated, containing $3.05 \mathrm{ppm}$ of humic acids, or $2.16 \mathrm{ppm}$ of atrazine, or $4.23 \mathrm{ppm}$ of symazine, as model compounds of natural substances or of common herbicides, which are notoriously present in aquifers, owing to contamination by agricultural activities [3, 4].

\section{MATERIALS AND METHODS}

2.1. Photocatalytic membranes. Metallic membranes used in the pilot plant (PHOTOMET ${ }^{\circledR}$ membranes $\mathbf{B I T / M 0 8}$ by B.I.T. srl, Milan, I), were prepared by a patented technology and contained the immobilised semiconductor with suitable photopromoting agents as a $3-4 \mu \mathrm{m}$ thick surface layer, directly produced on the nanotechnologically treated surface of these membranes by the manufacturer. CARBOPERM membranes $\boldsymbol{B I T} / \boldsymbol{C} \mathbf{1 2}$ by B.I.T. srl, Milan, Italy were prepared by a patented procedure, achieving immobilisation of $30 \mathrm{wt} . \%$ of pure active carbon onto ultra pure cellulose, as described [2].

2.2. Pilot plant experiments with tap water and with simulating solutions. The pilot plant experiments were carried out by using a PHOTOMET ${ }^{\circledR} \mathbf{W P} / \mathbf{K}$ prototype plant, kindly supplied by B.I.T. srl, Milan, I., able to operate continuously and employing molecular dioxygen dissolved in water, equilibrated with air, as oxygen donor. The absorbed power, as measured actinometrically, within the absorption range of semiconductor (from $395 \mathrm{~nm}$ downwards) was $9.6 \pm 0.4 \mathrm{~W}$, corresponding to $(1.46 \pm 0.09) \times 10^{-3}$ Einstein $\cdot \min ^{-1}$. Experiments performed in the present work used tap water (inorganic carbon IC content: $81.6 \pm 0.5 \mathrm{ppm}$; total organic carbon TOC content: $1.52 \pm 0.06 \mathrm{ppm}$ ) or simulating solutions. These simulating solutions being processed contained alternatively: $3.05 \mathrm{ppm}$ of humic acid (technical product by Fluka), or $2.16 \mathrm{ppm}$ of atrazine, or $4.23 \mathrm{ppm}$ of symazine. The $s$-triazines solutions were prepared by using partly purified technical products (purity 93-95\%), kindly supplied by OXON Italy (Pero, Milan, Italy). The solutions were prepared in ultra pure water (total organic carbon, TOC, content 4-5 ppb) and were saturated with pure cylinder air. No buffer system being added, $\mathrm{pH}$ varied from initial values of 5.9-6.7 to final values of 4.9-5.4 during the runs. The treated so- lutions were continuously fed to the photoreactor module from a polypropylene reservoir containing $5 \mathrm{~m}^{3}$ of these solutions. The polypropylene employed to manufacture the reservoir was unable to release organic contaminants above an ascertained level of $0.03 \pm 0.01 \mathrm{ppm}$ of carbon, even for prolonged residence times of ultra pure water in the reservoir.

The photocatalytic transformation of organic into inorganic carbon, either in tap water or in simulating solutions, was followed, by total organic carbon (TOC) analysis. To this purpose, a Shimadzu TOC-W instrument was used, by which the contribution of inorganic carbon present was always evaluated, in order to obtain TOC by difference from total carbon and inorganic carbon determinations. Due to the high sensitivity detector employed and the utilization of ultra pure water for preparation of solutions, when using the simulating solutions, determinations were accurate within 2$5 \mathrm{ppb} \mathrm{C}$. The instrument was equipped with the ASI-V self sampler.

As indicated by the Scheme of Figure 1, the tap water was fed through valve $\mathbf{A}$ to a pre filtration unit $\mathbf{C}$, fitting a $5 \mu \mathrm{m}$ porosity membrane made of food grade polypropylene, then to a second pre filtration unit $\mathbf{D}$, fitting a CARBOPERM membrane BIT/C12. A by pass valve $\mathbf{G}$ led the water to a reverse osmosis (RO) unit $\mathbf{M}$, which contained a RO membrane $\mathbf{F}$, able to produce, at a trans membrane pressure of 4 bar, $130 \mathrm{~L} /$ day of permeated water. The role of valve $\mathbf{G}$ was that of regulating the water softening degree, by bypassing a certain amount of the flux, while a non return valve $\mathbf{H}$ towards the tube I, through which the retentate water of the osmotic unit was discharged, a flow restriction valve $\mathbf{L}$, to regulate the water flux, and a shut off valve $\mathbf{N}$ integrated and completed the RO unit.

The outlet water permeating through the RO unit was collected in a reservoir $\mathbf{O}$, in which the irradiating unit, at the absorbed power described above, and the PHOTOMET ${ }^{\circledR}$ membranes BIT/M08, carried out the final photocatalytic treatment. A safety debacterisation unit $\mathbf{P}$, before the purified water outlet $\mathbf{Q}$ was added, just to comply formally with the Italian legislation, which aims to assure a standing disinfection and debacterisation, before the end use, even if in the pilot plant of the present study this was overdue, owing to the previous photocatalytic action.

Efficiency of treatment by this prototype pilot plant was compared by carrying out parallel experiments, using two other commercial plants (I and II), available for the same purpose as that of the prototype used in the present work, but in which the photocatalytic treatment was not provided for. In all the three plants, anyway, a final and standard UV treatment was imparted, as required by the Italian legislation, to assure a standing disinfection and debacterisation, before the end use, even if in the pilot plant of the present study this was overdue, as remarked above. 


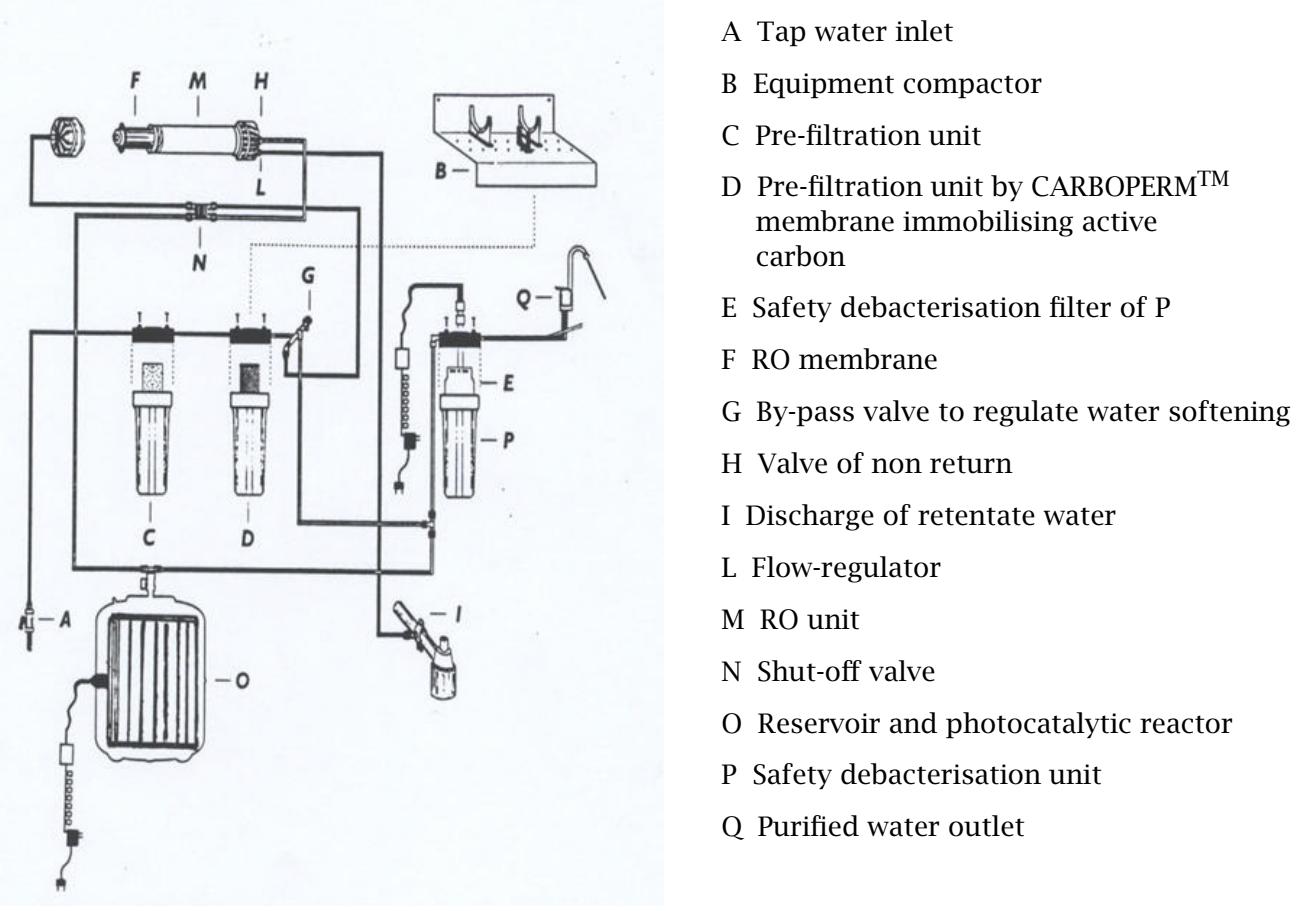

Figure 1. Schematic layout of PHOTOMET ${ }^{\circledR} \mathrm{WP} / \mathrm{K}$ pilot plant.

Table 1. Total organic carbon (TOC) and inorganic carbon (IC), both expressed as ppm of carbon, as measured at the outlet of two commercial domestic plants (I and II), and at the outlet of PHOTOMET ${ }^{\circledR}$ WP/K prototype plant (by B.I.T. srl, Milan, I.), in two experimental conditions, either with the photocatalytic mineralization unit switched off or with this unit switched on. Uncertainties are expressed as standard deviations of at least 400 series of measurements for each plant, each series being repeated five times. Initial TOC and IC contents of tap water employed were IC: $81.6 \pm 0.5 \mathrm{ppm}$; TOC: $1.52 \pm 0.06 \mathrm{ppm}$ (no standard deviations outside the specified limits could be substantially observed, even during the relative long duration of the experiments).

\begin{tabular}{|c|c|c|c|c|}
\hline Tested plants & IC (ppm) & $\begin{array}{c}\text { Percent } \\
\text { abatement of IC }\end{array}$ & TOC (ppm) & $\begin{array}{c}\text { Percent } \\
\text { abatement of TOC }\end{array}$ \\
\hline Plant I & $7.86 \pm 0.05$ & $90.4 \%$ & $1.12 \pm 0.02$ & $26.3 \%$ \\
\hline Plant II & $6.01 \pm 0.05$ & $92.6 \%$ & $0.908 \pm 0.009$ & $40.3 \%$ \\
\hline \multicolumn{5}{|l|}{ PHOTOMET ${ }^{\circledR}$} \\
\hline $\begin{array}{l}W P / K \text { plant with } \\
\text { photoreactor off }\end{array}$ & $6.15 \pm 0.04$ & $92.5 \%$ & $0.989 \pm 0.008$ & $34.9 \%$ \\
\hline \multicolumn{5}{|l|}{ PHOTOMET ${ }^{\circledR}$} \\
\hline $\begin{array}{l}W P / K \text { plant with } \\
\text { photoreactor on }\end{array}$ & $6.13 \pm 0.05$ & $92.5 \%$ & $0.06 \pm 0.02$ & $96.1 \%$ \\
\hline
\end{tabular}

\section{RESULTS AND DISCUSSION}

3.1. Pilot plant experiments with tap water. In a first series of runs, pilot plants I and II, as well as prototype pilot plant used in the present work, have been tested by using tap water of the Milan municipal waterworks, in order to determine their relative efficiencies. Results are collected in Table 1, in which uncertainties are expressed as standard deviations of at least 400 se- ries of measurements for each plant, each series being repeated five times and protracted for at least 10-15 days.

It may be easily observed, that the three plants, when the pilot photocatalytic unit of the present paper was switched off, behaved similarly in their inability to wipe out other than a very small part of the organic contamination. This is obvious, if the real limits of reverse osmosis membranes in rejecting organic solutes, 
Table 2. Percent abatement of total organic carbon (TOC) in experiments using solutions simulating natural and contaminated aquifers (see Introduction and Experimental part). These simulating solutions contained alternatively: 3.05 ppm of humic acid, or $2.16 \mathrm{ppm}$ of atrazine, or $4.23 \mathrm{ppm}$ of symazine. The plants tested were two commercial domestic plants (I and $\mathrm{II})$, and the PHOTOMET ${ }^{\circledR} \mathrm{WP} / \mathrm{K}$ prototype plant, set up in the present work.

\begin{tabular}{lccc}
\hline Tested plants & $\begin{array}{c}\text { Percent abatement of } \\
\text { TOC from humic } \\
\text { acid solutions }\end{array}$ & $\begin{array}{c}\text { Percent abatement of } \\
\text { TOC from atrazine } \\
\text { solutions }\end{array}$ & $\begin{array}{c}\text { Percent abatement of } \\
\text { TOC from symazine } \\
\text { solutions }\end{array}$ \\
\hline $\begin{array}{l}\text { Plant I } \\
\text { Plant II }\end{array}$ & $25 \pm 1 \%$ & $16 \pm 2 \%$ & $14 \pm 2 \%$ \\
$\boldsymbol{P H O T O M E T}^{\circledR} \boldsymbol{W P} / \boldsymbol{K}$ & $39 \pm 2 \%$ & $24 \pm 1 \%$ & $27 \pm 2 \%$ \\
$\begin{array}{l}\text { plant with } \\
\text { photoreactor on }\end{array}$ & $94 \pm 2 \%$ & $96 \pm 3 \%$ & $93 \pm 3 \%$ \\
\hline
\end{tabular}

and particularly medium or low molecular weight solutes, are considered. On the contrary, the outstanding efficiency of the photocatalytic membrane reactor clearly emerges, as being able to remove, by photocatalytic mineralisation, more than $95 \%$ of the organic carbon content.

\subsection{Pilot plant experiments with simulating so-} lutions. In order to compare further efficiency of these plants, as regards integral photomineralisation of organic micropollutants present in groundwaters, simulated feed solutions were also tested, containing $3.05 \mathrm{ppm}$ of humic acids, or $2.16 \mathrm{ppm}$ of atrazine, or $4.23 \mathrm{ppm}$ of symazine (see Experimental part). The percent TOC abatements of the different plants are reported in Table 2.

Some features may be readily observed and some conclusions drawn:

(1) As regards abatement of humic acids, the performance of plants I and II is substantially the same as that observed in the corresponding values, reported in Table 1, relatively to tap water experiments, while in the prototype plant, which is the object of the present study, photocatalytic abatement of TOC is virtually complete. On the contrary, if TOC abatements relative to atrazine or symazine solutions are compared with those of humic acid solutions, performance of plants I and II sensibly decreases.

(2) The behaviour remarked above may mean either that the adsorption units of plants I and II work less satisfactorily as regards adsorption of $s$-triazines used as model molecules of herbicides, or, independently of adsorption efficiencies of these plants, the rejection coefficients of the osmotic units are the controlling factors. If the latter hypothesis, which is indeed the most probable, should hold, this would denote that, in the tap water used, organic components are substantially, or prevailingly, humic acids. The high molecular weight of the latter allows then to rely on relatively higher rejection coefficients by reverse osmosis. On the contrary, with decrease of molecular weight ( $s$-triazines), the rejection coefficients somewhat decrease, and consequently the concentrations of these organics in the permeate increase.

(3) As regards the prototype plant of the present study, the photocatalytic unit plays the most relevant role in controlling overall efficiency of TOC abatement, even if a modest, but insufficient, contribution by the reverse osmosis unit is operating, as shown by data of Table 1, when the photocatalytic unit is switched off.

(4) The role of the reverse osmosis unit, in all of the plants tested, appears to consist mainly in reducing the inorganic ions content of the treated water, rather than in acting efficiently on TOC abatement. This reduction of salinity may be a commercial goal in Countries where calcium ion content of water is very high, and thus the "apparent" quality of drinking waters, regarding this excess salinity, may be improved; but it's not a recommended practice by the WHO [5], due to the important role of this ion in human health. Consequently, limitation of the use of reverse osmosis in these plants, and adoption of photocatalytic processes, to reduce contamination deriving from organic and microbiological pollutants as well as from toxins, should constitute a much better philosophy, as regards the health protection, and a more effective way to drastically suppress potential damage by these really harmful contaminants.

\section{CONCLUSIONS}

The pilot plant, set up and investigated in the present work, represents a very effective solution to the problem of integral purification and mineralisation of trace amounts of polluting agents, such as herbicides and others, either natural (humic substances) or due to anthropogenic origin, from drinking water.

Commercial plants, equipped with a reverse osmosis unit, even if coupled with an active carbon adsorption unit, do not act efficiently on TOC abatement. The photocatalytic unit of the pilot plant described in the present paper, based on a trustworthily designed 
photocatalytic membrane photoreactor, on the contrary, implements very satisfactorily the traditional technology, and is able to mineralise much more of $90 \%$ of TOC. even at very low level of contamination.

\section{REFERENCES}

[1] I. R. Bellobono and L. Righetto, New Aspects of Radiation Curing in Polymer Science and Technology (J. P. Fouassier and J. F. Rabek, eds.), Elsevier, Barking, UK, 1993, Vol. 4, ch. 5, pp. 151-177.
[2] I. R. Bellobono et al., Membrane Separation Processes (A. Green, ed.), BHR, Cranfield, Bedford, UK, 1989, pp. 187-193.

[3] R. Frank, B. S. Clegg, C. Sherman, and N. D. Chapman, Arch. Environ. Contam. Toxicol. 19 (1990), 319.

[4] A. Di Corcia, R. Samperi, A. Marcomini, and S. Stellato, Anal. Chem. 65 (1993), 907.

[5] World Health Organization (WHO), Guidelines for Drinking Water Quality, vol. 1: Recommendations, WHO, Geneva, CH, 1993. 


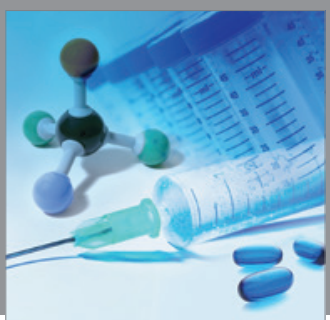

International Journal of

Medicinal Chemistry

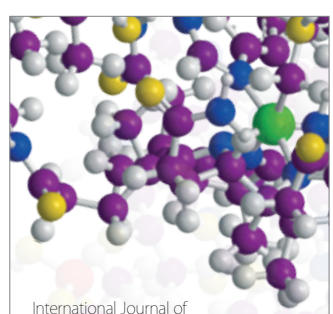

Carbohydrate Chemistry

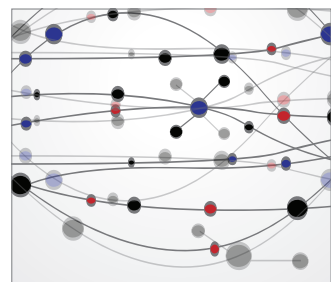

The Scientific World Journal
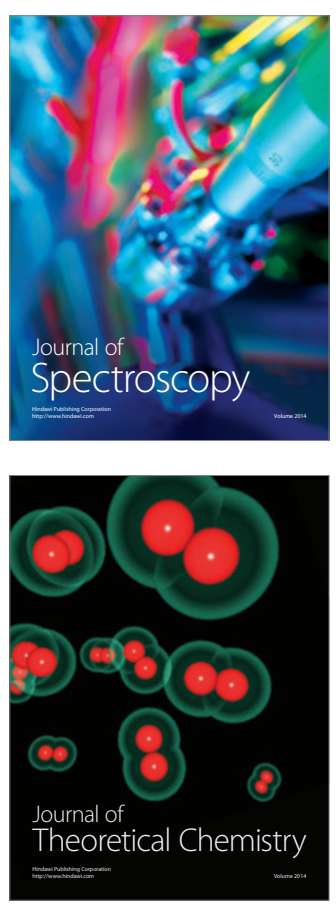
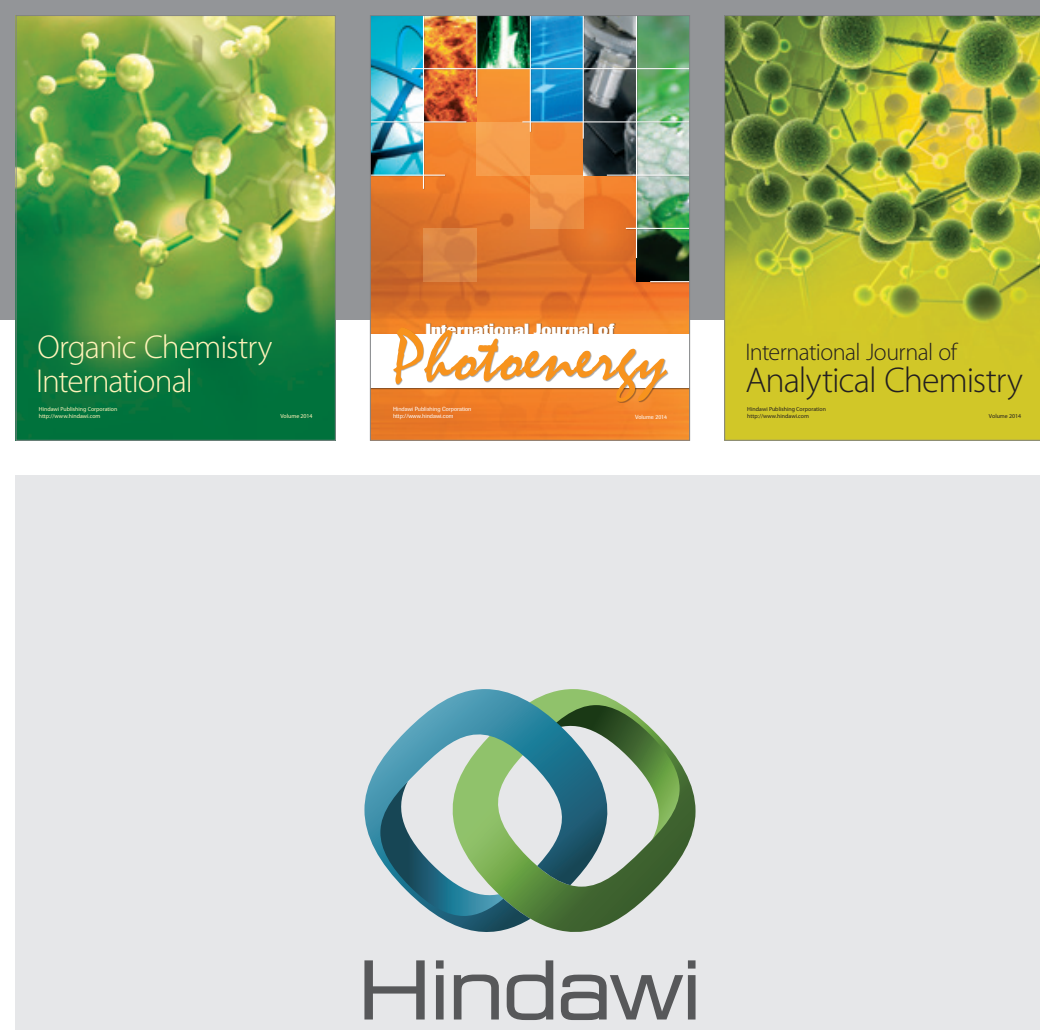

Submit your manuscripts at

http://www.hindawi.com
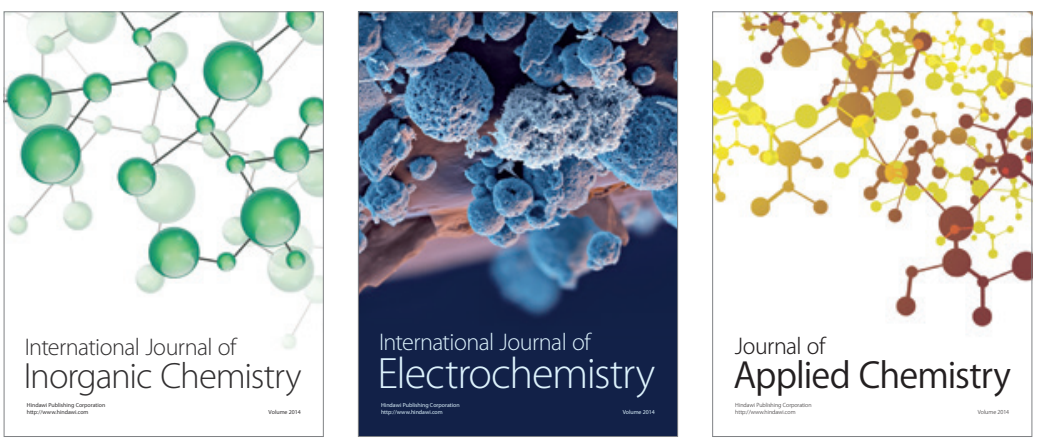

Journal of

Applied Chemistry
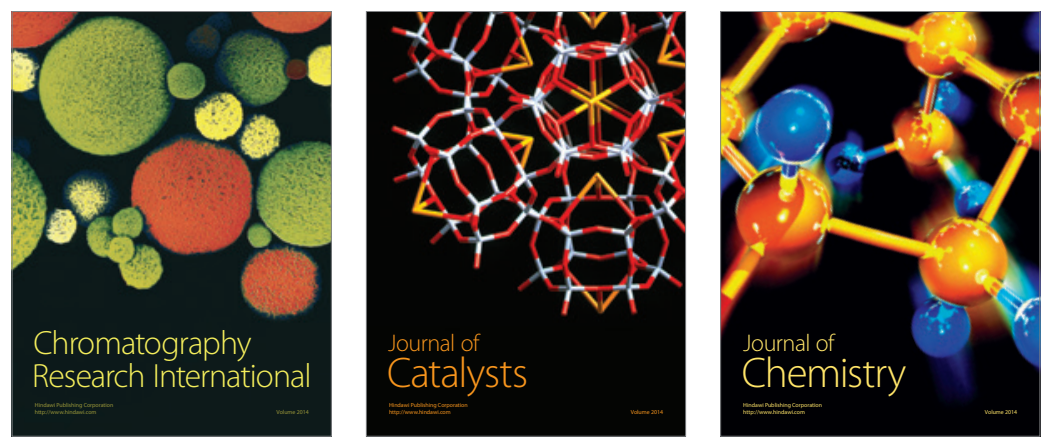
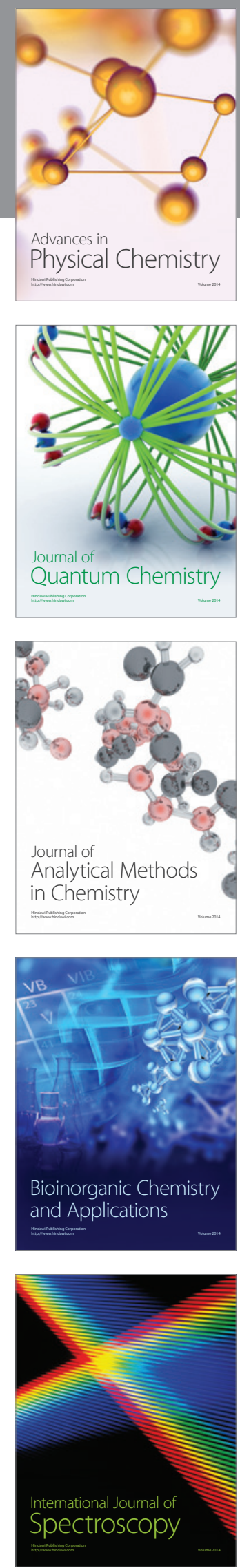